\title{
The Effect of Nitroglycerine Infusion on Postoperative Pain in Lower Limb Surgery: A Clinical Double-Blind Study
}

\author{
Poupak Rahimzadeh ${ }^{1}$, Seyed Hamid Reza Faiz ${ }^{1}$, Farnad Imani ${ }^{1}$, Atoosa Soltani ${ }^{1}$ and Pooya \\ Derakhshan ${ }^{1, *}$ \\ ${ }^{1}$ Pain Research Center, Iran University of Medical Sciences, Tehran, Iran \\ "Corresponding author: Assistant Professor of Anesthesiology, Pain Research Center, Iran University of Medical Sciences, Tehran, Iran. Email: p.derakhshan.rcrdc@gmail.com
} Received 2019 May 16; Revised 2019 July 07; Accepted 2019 August 13.

\begin{abstract}
Background: Acute postoperative pain causes severe discomfort in patients accompanied by hemodynamic and metabolic instability.

Objectives: The aim of this study was to evaluate the effects of nitroglycerin addition on the infusion of intravenous analgesia pump in patients with lower limb orthopedic surgery.

Methods: This study was a double-blind clinical trial conducted on 75 patients with lower limb fracture. Patients were randomly assigned to receive three regimens for postoperative pain control via intravenous analgesia pump, including group A (fentanyl $10 \mathrm{mc} / \mathrm{kg}+10 \mathrm{~mL}$ distilled water), B (fentanyl $10 \mathrm{mc} / \mathrm{kg}+$ nitroglycerin $500 \mathrm{mc}$ ), and C (fentanyl $10 \mathrm{mc} / \mathrm{kg}+$ nitroglycerin $1000 \mathrm{mc}$ ). The patients at the beginning of recovery and prior to putting the pain pump at the time of 4, 8, 12, 24, and 48 hours, were assessed with visual analogue scale (VAS) to measure pain and Ramsay scale to measure sedation.

Results: The results showed that weight, height, and gender distribution were not significantly different in the three groups. The HR, MAP, and VAS mean scores showed a significant difference for intragroup and intergroup differences in the three groups at many times.

Conclusions: Low dose nitroglycerine, as an adjuvant drug, can be added to intravenous patient-controlled analgesia pump in patients undergoing surgery for better analgesic purposes in patients without underlining disease.
\end{abstract}

Keywords: Nitroglycerine, Intravenous Analgesia, Orthopedic Surgery, Pain, Fentanyl

\section{Background}

Insufficient relief of postoperative pain is accompanied by complications such as long recovery and hospitalization, an increase of hospital costs, and reduction of patient's satisfaction score (1). Effective management of postoperative pain is currently a part of the surgical process and not only reduces the patient suffering but also reduces mortality and promotes rapid hospital discharge, improves patient's quality of life, and reduces hospital costs (1-4). Patient-controlled intravenous analgesia (PCIA) is an effective method for pain control, which has entered the literature since 1990 (5). Since the introduction of an analgesic pump, the usefulness of this method has been evaluated in contrast to the conventional nurse controlled analgesia (NCA) method. Advantages of the PCIA method include reducing the waiting time of the patient from pain sensation to pain relief, the workload of personnel and nurses and the probability of medical errors, and record- ing the injected dose more precisely(6). On the other hand, studies have shown that PCA has a greater reduction in pain intensity and better efficacy in controlling pain than other analgesics. However, these systems have some disadvantages such as device cost or lack of bolus injection in some models, which can lead to periods of silence and pain intensity in the patients (7).

Owing to some side effects such as drug overdose, delayed analgesia onset and ineffective postoperative pain control, some limitations occur; thus adding adjuvants, especially to opioid pumps has been proposed to decrease these problems (5). Recent studies have shown the beneficial role of adding nitroglycerin to other analgesic drugs such as lidocaine to upgrade the motor and sensory blockade, tourniquet pain, and postoperative analgesia. Even though the results are controversial due to different drug doses (8-12). Studies have also shown that transdermal nitroglycerin is effective in improving the analgesic effect of opium with nitric oxide release mechanism. It means that 
opium produces nitric oxide, in which increases the intracellular cGMP concentration to modulate the transfer of pain in the central and peripheral nervous system (13-16) and it can be used as an additive and may synergistically affect opioid by these mechanisms.

\section{Objectives}

Since there has been no previous study on the postoperative analgesic effect of intravenous nitroglycerine, the aim of this study was to evaluate the effects of nitroglycerin addition on the infusion of intravenous analgesia pump in patients with lower limb orthopedic surgery.

\section{Methods}

This study is a double-blind clinical trial conducted on 75 patients with tibia, fibula, and distal femur fracture. Qualified patients who underwent orthopedic surgeries were randomly divided into three groups using random number table. The inclusion criteria were patients aged 18 - 50 years, ASA I and II, blood loss less than available blood loss during surgery and surgery duration less than two hours. The method of anesthesia for these patients was spinal anesthesia with $15 \mathrm{mg}$ bupivacaine $0.5 \%$, without the use of any intravenous opioid for sedation. Exclusion criteria were lack of patient dissatisfaction to continue the study, sensitivity to any of the studied drugs, seizure, addiction to alcoholism, benzodiazepine and opium, heart failure, arrhythmia and valvular heart failure, Hypertension, and any history of neurological defects.

In this study after completing descriptions for the patients, written informed consent was obtained before the entrance to the operating room. All patients were randomly assigned to three groups of 25 patients using an intravenous analgesia pump (accufuser CTx, South Korea) at an infusion rate of $6 \mathrm{ml} / \mathrm{h}$ as follows:

Group A: 25 patients with fentanyl $10 \mathrm{mc} / \mathrm{kg}+10 \mathrm{~mL}$ distilled water $+100 \mathrm{~mL}$ normal saline.

Group B: 25 patients with fentanyl $10 \mathrm{mc} / \mathrm{kg}$ (Caspian, Iran) + nitroglycerin 500 mc (Caspian, Iran) diluted in 10 $\mathrm{mL}$ distilled water and then diluted with $100 \mathrm{~mL}$ normal saline.

Group C: 25 patients with fentanyl $10 \mathrm{mc} / \mathrm{kg}$ + nitroglycerin $1000 \mathrm{mc}$ diluted in $10 \mathrm{~mL}$ distilled water and then diluted with $100 \mathrm{~mL}$ normal saline.

The patients at the beginning of the recovery room and prior to putting the pain pump and at the time of $4,8,12$, 24 , and 48 hours later were assessed with visual analogue scale (VAS) to measure pain and Ramsay scale to measure sedation score. Meperidine $0.2 \mathrm{mg} / \mathrm{kg}$ was injected into the patient when the VAS score was more than 4 . Patients were examined for hemodynamic, systolic blood pressure, diastolic blood pressure, mean arterial pressure, and heart rate in all times (SAADAT ALBORZ B5, Iran).

At each studied time, if the patient has side effects, including a heart rate $>120$, heart rate $<50,90 \mathrm{mmHg}<$ $\mathrm{SBP}>190 \mathrm{mmHg}$, nausea and vomiting more than 3 times, and severe headache, the patient's PCIA pump discontinued and the patient was excluded. Also, in the event of $\mathrm{a} \geq$ $20 \%$ drop in the patient's blood pressure, the infusion was discontinued and it was noted. In case of nausea and vomiting, $4 \mathrm{mg}$ of Ondansetron IV was injected. All patients were blind regarding how to collect and record data as well as the kind of medication used in this study.

\subsection{Statistical Analysis}

Descriptive results were presented as mean \pm SD or percentages. $T$-test was used to compare means. ANOVA repeated measure was used to compare the mean of quantitative variables over time. P value $<0.05$ was considered significant. The data were analyzed using SPSS version 21 software.

\section{Results}

In this study, the weight, gender, and age of the patients in the three groups were compared using one-way ANOVA. The results showed that weight, height, and gender distribution were not significantly different in the three groups ( $\mathrm{P}>0.05$ ). Table 1 shows the demographic characteristics of the three groups in this study. No statistical difference was shown in terms of operation type $(\mathrm{P} \geq$ 0.05). Figure 1 shows the flowchart diagram of the present study.

The mean scores of heart rate (HR) for the three groups $\mathrm{A}, \mathrm{B}$, and $\mathrm{C}$ at $4,8,12,24$, and 48 hours after surgery showed that HR at 8,12 , and 24 hours had a significant difference ( $P$ $<0.05$ ), but for the 4 and 48 hours after the surgery was not significant $(\mathrm{P}>0.05)$. The results of follow-up tests were as follows: the mean HR in 8,12 , and 24 for group $C$ was significantly higher than group $\mathrm{A}$ and $\mathrm{B}(\mathrm{P}<0.05)$ (Table 2 and Figure 2).

The results showed that there was a significant difference among the three groups at the studied times for $\mathrm{HR}$ $(\mathrm{P}<0.001)$. Regarding MAP scores for the three groups A, B, and $\mathrm{C}$, there was a significant difference, except for time 4 and 8 hours after the surgery $(\mathrm{P}<0.05)$. Table 3 shows the results of One-way ANOVA test for the MAP at the studied time. There was no significant difference in the intragroup effects among the treatment groups over time $(\mathrm{P}=0.051)$. In the intergroup analysis, the results also showed that 


\begin{tabular}{|c|c|c|c|c|}
\hline Variable & $A(N=25)$ & B $(\mathbf{N}=25)$ & $C(N=25)$ & P Value \\
\hline Age, Mean \pm SD & $48.20 \pm 17.53$ & $49.54 \pm 14.93$ & $48.28 \pm 17.58$ & 0.952 \\
\hline Weight, Mean \pm SD & $74.48 \pm 15.89$ & $74.73 \pm 9.74$ & $72.63 \pm 10.72$ & 0.821 \\
\hline Gender, No. (\%) & & & & 0.577 \\
\hline Female & $13(52.00)$ & $15(60.00)$ & $12(48.00)$ & \\
\hline Male & $12(48.00)$ & $10(40.00)$ & $13(52.00)$ & \\
\hline
\end{tabular}

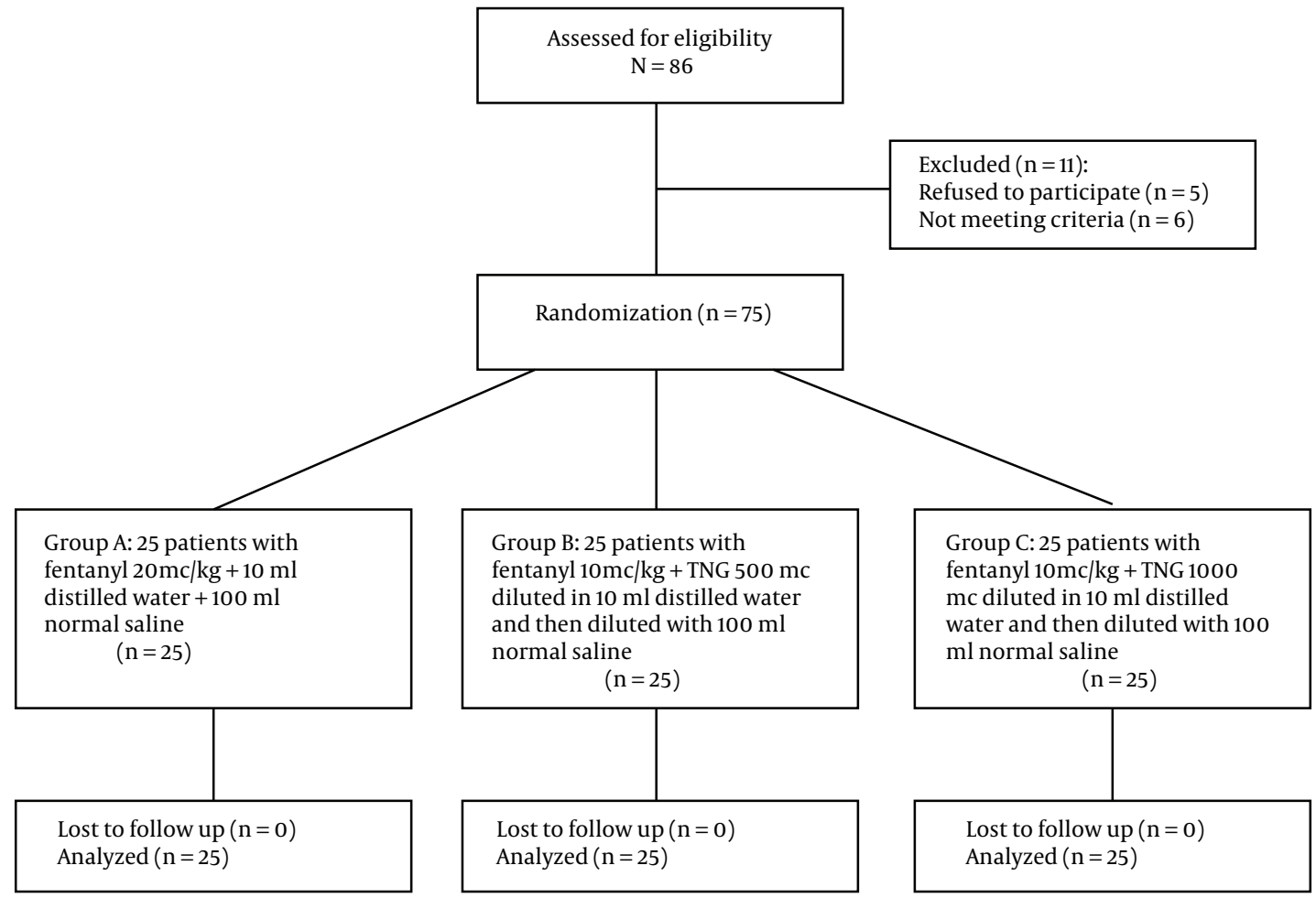

Figure 1. Flowchart diagram of this study

there was a significant difference among the three groups over time $(\mathrm{P}<0.001)$. Figure 3 shows the trend and error bar of MAP in the three groups at different times.

Regarding VAS among the three groups A, B, and C, the results showed that there was significantly different in the three groups $(P<0.05)$. Table 4 shows the results of ANOVA for VAS at the studied time. For intragroup effects, there was a significant difference between the treatment groups over time $(\mathrm{P}<0.001)$. In the intergroup analysis, the results also showed that there was a significant difference between the three groups over time $(\mathrm{P}<0.001)$. Figure 4 shows the trend and error bar of VAS for the three groups at different times.

\section{Discussion}

This study was designed to evaluate the effects of adding nitroglycerin to the opioid in intravenous analgesia pump for reducing the dose of other analgesics and increasing the efficacy of drugs or reducing postoperative pain. The HR, MAP, and VAS mean scores showed a significant difference in terms of intragroup and intergroup effects in the three groups. Our study shows that pain was lower in patients receiving a higher dose of nitroglycerin (group C). Although the effect of nitroglycerin on hemodynamic was higher in this situation, MAP and HR did not show clinically significant differences among the three groups. We advise the group B nitroglycerin dosage for reducing the pain and less hemodynamic changes during infusion. It has been seen in previous studies that cutaneous 


\begin{tabular}{|c|c|c|c|c|}
\hline Variable & Mean & Std. Deviation & $\mathbf{F}$ & PValue $^{a}$ \\
\hline HR 4 & & & 0.520 & 0.597 \\
\hline A & 78.44 & 10.433 & & \\
\hline B & 77.04 & 17.707 & & \\
\hline C & 80.68 & 7.983 & & \\
\hline HR 8 & & & 9.196 & $<0.001$ \\
\hline A & 75.68 & 8.688 & & \\
\hline B & 76.32 & 8.562 & & \\
\hline C & 84.32 & 6.342 & & \\
\hline HR 12 & & & 7.695 & 0.001 \\
\hline A & 76.00 & 7.632 & & \\
\hline B & 77.04 & 9.085 & & \\
\hline C & 84.16 & 7.174 & & \\
\hline HR 24 & & & 7.586 & 0.001 \\
\hline A & 75.68 & 6.650 & & \\
\hline B & 75.12 & 7.384 & & \\
\hline C & 82.00 & 6.752 & & \\
\hline HR 48 & & & 1.985 & 0.145 \\
\hline A & 74.76 & 7.429 & & \\
\hline B & 75.92 & 11.228 & & \\
\hline C & 79.38 & 5.404 & & \\
\hline
\end{tabular}

${ }^{\mathrm{a}} \mathrm{P}$ value $<0.05$ was considered significant.

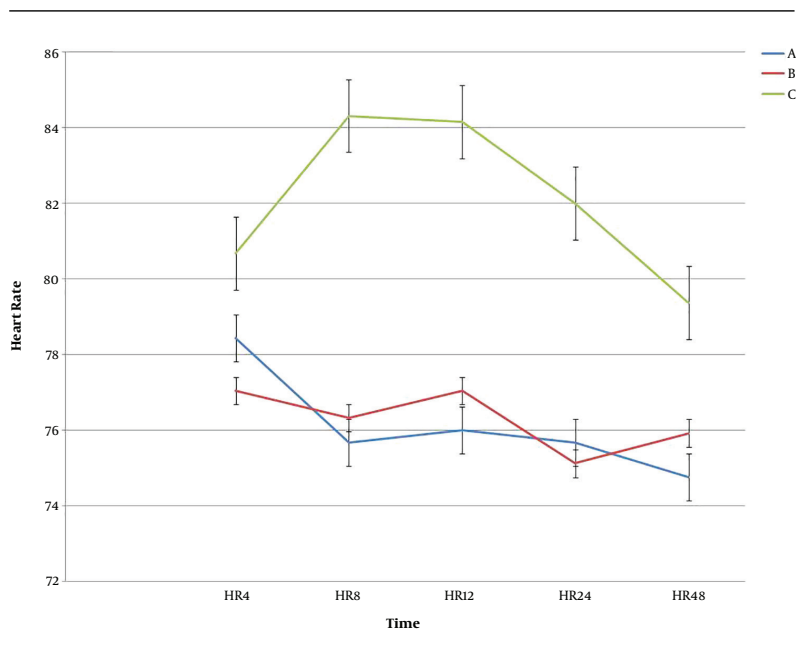

Figure 2. Trend and error bar for heart rate in the three groups at different times

nitroglycerine increased the duration of spinal anesthesia during and after the surgery and this drug has not been used via PCIA $(4,6,7,17)$.

In the study of Sen et al., they determine that the addi-

\begin{tabular}{|c|c|c|c|c|}
\hline Variable & Mean & Std. Deviation & $\mathbf{F}$ & PValue \\
\hline MAP 4 & & & 1.49 & 0.231 \\
\hline A & 126.04 & 17.53 & & \\
\hline B & 97.77 & 11.12 & & \\
\hline C & 94.06 & 13.65 & & \\
\hline MAP 8 & & & 11.03 & $<0.001$ \\
\hline A & 99.12 & 10.64 & & \\
\hline B & 91.94 & 7.03 & & \\
\hline C & 84.98 & 13.29 & & \\
\hline MAP 12 & & & 24.03 & $<0.001$ \\
\hline A & 98.09 & 9.98 & & \\
\hline B & 91.38 & 6.88 & & \\
\hline C & 79.00 & 12.46 & & \\
\hline MAP 24 & & & 14.10 & $<0.001$ \\
\hline A & 96.90 & 9.88 & & \\
\hline B & 88.46 & 6.32 & & \\
\hline C & 82.90 & 11.24 & & \\
\hline MAP 48 & & & 8.47 & $<0.001$ \\
\hline A & 95.52 & 7.87 & & \\
\hline B & 86.97 & 6.83 & & \\
\hline C & 81.76 & 17.83 & & \\
\hline
\end{tabular}

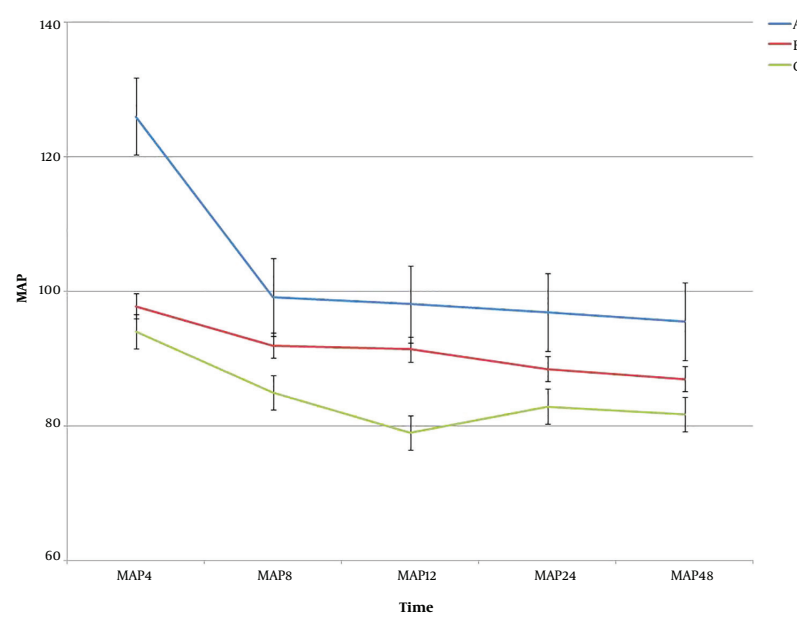

Figure 3. Trend and error bar for MAP in the three groups at different times

tion of nitroglycerine to lidocaine for Intravenous regional anesthesia may improve motor and sensory blockade, decrease tourniquet pain, and better postoperative analgesia without side effects (18). In the present study, the addition of nitroglycerin increased analgesia in the third group, the 


\begin{tabular}{|c|c|c|c|c|}
\hline Variable & Mean & Std. Deviation & $\mathbf{F}$ & P Value \\
\hline VAS 4 & & & 4.407 & 0.016 \\
\hline A & 3.92 & 1.25 & & \\
\hline B & 3.20 & 1.00 & & \\
\hline $\mathrm{C}$ & 2.83 & 1.60 & & \\
\hline VAS 8 & & & 7.675 & 0.001 \\
\hline A & 3.12 & 1.23 & & \\
\hline B & 2.08 & 0.95 & & \\
\hline $\mathrm{C}$ & 1.96 & 1.24 & & \\
\hline VAS 12 & & & 9.709 & $<0.001$ \\
\hline A & 2.60 & 1.00 & & \\
\hline B & 1.80 & 0.76 & & \\
\hline $\mathrm{C}$ & 1.52 & 0.91 & & \\
\hline VAS 24 & & & 9.971 & $<0.001$ \\
\hline A & 2.24 & 0.77 & & \\
\hline B & 1.48 & 0.65 & & \\
\hline $\mathrm{C}$ & 1.40 & 0.76 & & \\
\hline VAS 48 & & & 13.442 & $<0.001$ \\
\hline A & 1.88 & 0.60 & & \\
\hline B & 1.20 & 0.50 & & \\
\hline $\mathrm{C}$ & 1.20 & 0.50 & & \\
\hline
\end{tabular}

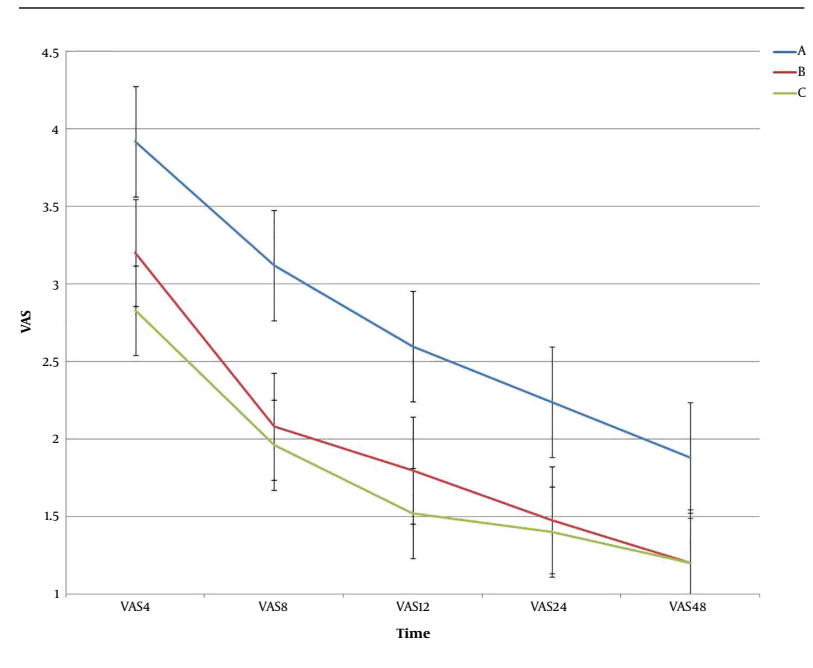

Figure 4. Trend and error bar for VAS in the three groups at different times

nitroglycerin dose was higher than the second group, and the mean VAS was lower as well.

In the study of Orbach-Zinger et al., nitroglycerin patches showed no advantage in patients receiving PCA of morphine analgesia after total knee replacement. There- fore, they realized that the safety of using nitroglycerin patch after the surgery must be investigated more (11), this finding was inconsistent with our study and it seems the cause of this difference is the dosage of nitroglycerin in these two studies and underlying disease of studied patients as well.

In the study of Lauretti et al., they found that neither intrathecal 5 microgram neostigmine alone nor transdermal nitroglycerin alone ( $5 \mathrm{mg} /$ day) postponed the time of first rescue analgesic requirements. The mixture of both providing good postoperative analgesia after vaginoplasty indicated that transdermal nitroglycerin and the intrathecal neostigmine may improve each other's antinociceptive special effects (19). Consistent with our study, nitroglycerin enhanced the antinociceptive effects of fentanyl in the intravenous infusion route by PCA.

Further studies in the future are recommended to investigate nitroglycerin effects as a postoperative analgesic adjuvant via pump infusion or other modalities. In patients with comorbidities such as ischemic heart disease or diabetes mellitus and hypertension, it can be investigated more to see the effects on hemodynamic status because MAP decline can be achieved by adding nitroglycerine in PCIA pump, which could lead to other side effects. Considering this possible problem, we recommend nitroglycerin usage in hemodynamically stable patients.

\subsection{Conclusions}

According to the results, nitroglycerine, as an adjuvant drug, can be added to the intravenous analgesia pump in patients undergoing surgery for better analgesic purposes. However, we recommend that nitroglycerin should be used in hemodynamically stable patients.

\section{Acknowledgments}

The authors wish to thank Rasoul Akram Hospital Clinical Research Development Center, Iran University of Medical Sciences.

\section{Footnotes}

Authors' Contribution: Study concept and design: Poupak Rahimzadeh and Hamid Reza Faiz; analysis and interpretation of data: Pooya Derakhshan, A Soltani and Farnad Imani; drafting of the manuscript: Poupak Rahimzadeh and Hamid Reza Faiz; critical revision of the manuscript for important intellectual content: Hamid Reza Faiz, A Soltani, and Pooya Derakhshan; statistical analysis: Pooya Derakhshan, Farnad Imani and Poupak Rahimzadeh. 
Clinical Trial Registration Code: The study registered at the Iranian Registry of Clinical Trials under the code of IRCT20170716035126N1.

Conflict of Interests: None declared by the authors.

Ethical Approval: After obtaining the necessary permissions, including the ethics code R.IUMS.FMD.REC1396.9411174009, the RCT code, and written permission from the authorities of the Rasoul Akram educational center in Tehran, the researcher explained the research and education for patients emphasizing their information would remain confidential and the results of the research would be published anonymously, and they could leave the study at any time.

Funding/Support: None declared by the authors.

Patient Consent: Informed consent was obtained from all individuals.

\section{References}

1. Sedighinejad A, Haghighi M, Naderi Nabi B, Rahimzadeh P, Mirbolook A, Mardani-Kivi M, et al. Magnesium sulfate and sufentanil for patientcontrolled analgesia in orthopedic surgery. Anesth Pain Med.2014;4(1). e11334. doi: 10.5812/aapm.11334. [PubMed: 24660152]. [PubMed Central: PMC3961029].

2. Hudcova J, McNicol E, Quah C, Lau J, Carr DB. Patient controlled opioid analgesia versus conventional opioid analgesia for postoperative pain. Cochrane Database Syst Rev. 2006;(4). CD003348. doi: 10.1002/14651858.CD003348.pub2. [PubMed: 17054167].

3. Gramke HF, de Rijke JM, van Kleef M, Raps F, Kessels AG, Peters $\mathrm{ML}$, et al. The prevalence of postoperative pain in a cross-sectional group of patients after day-case surgery in a university hospital. Clin JPain. 2007;23(6):543-8. doi: 10.1097/AJP.0b013e318074c970. [PubMed: 17575496].

4. Faiz HR, Rahimzadeh P, Visnjevac O, Behzadi B, Ghodraty MR, Nader ND. Intravenous acetaminophen is superior to ketamine for postoperative pain after abdominal hysterectomy: Results of a prospective, randomized, double-blind, multicenter clinical trial. J Pain Res. 2014;7:65-70. doi: 10.2147/JPR.S53234. [PubMed: 24465135]. [PubMed Central: PMC3900330].

5. Grass JA. Patient-controlled analgesia. Anesth Analg. 2005;101(5 Suppl):S44-61. doi: 10.1213/01.ane.0000177102.11682.20. [PubMed: 16334492].

6. Nikolajsen L, Haroutiunian S. Intravenous patient-controlled analgesia for acute postoperative pain. Eur Pain Suppl. 2011;5(S2):453-6. doi: 10.1016/j.eujps.2011.08.045.

7. Momeni M, Crucitti M, De Kock M. Patient-controlled analgesia in the management of postoperative pain. Drugs. 2006;66(18):2321-37. doi: 10.2165/00003495-200666180-00005. [PubMed:17181375].
8. Derakhshan P, Karbasy SH, Bahador R. The effects of nitroglycerine on pain control during the propofol injection; a controlled, doubleblinded, randomized clinical trial.Anesthesiol Pain Med.2015;5(3).doi: 10.5812/aapm.5(3)2015.26141.

9. Higa M, Takasu N, Tamanaha T, Nakamura K, Shimabukuro M, Sasara $\mathrm{T}$, et al. Nitroglycerin spray rapidly improves pain in a patient with chronic painful diabetic neuropathy. Diabet Med. 2004;21(9):1053-4. doi: 10.111//j.1464-5491.2004.01280.x. [PubMed: 15317617].

10. Lauretti GR, Lima IC, Reis MP, Prado WA, Pereira NL. Oral ketamine and transdermal nitroglycerin as analgesic adjuvants to oral morphine therapy for cancer pain management. Anesthesiology. 1999;90(6):1528-33. doi: 10.1097/00000542-199906000-00005. [PubMed: 10360847].

11. Orbach-Zinger S, Lenchinsky A, Paul-Kesslin L, Velks S, Salai M, Eidelman LA. Transdermal nitroglycerin as an adjuvant to patientcontrolled morphine analgesia after total knee arthroplasty. Pain Res Manag. 2009;14(2):109-12. doi: 10.1155/2009/817837. [PubMed: 19532851]. [PubMed Central: PMC2706646].

12. Siamdoust SAR, Faiz SHR, Derakhshan P, Sakhayi M. Evaluation the analgesic effect of nitroglycerine added to lidocaine in intravenous regional anesthesia. J Anesthiol Pain. 2011;1(3):17-23.

13. Bansal P, Baduni N, Bhalla J, Mahawar B. A comparative evaluation of magnesium sulphate and nitroglycerine as potential adjuncts to lidocaine in intravenous regional anaesthesia. Int J Crit Illn Inj Sci. 2015;5(1):27-31. doi: 10.4103/2229-5151.152324. [PubMed: 25810961]. [PubMed Central: PMC4366824].

14. Cakmak BM, Cakmak G, Akpek E, Arslan G, Sahin MS. Peri- and postanalgesic properties of lidokain, lornoxicam, and nitroglycerine combination at intravenous regional anesthesia. Biomed Res Int. 2014;2014:737109. doi: 10.1155/2014/737109. [PubMed: 24734241]. [PubMed Central: PMC3966418].

15. Toda N, Kishioka S, Hatano Y, Toda H. Modulation of opioid actions by nitric oxide signaling. Anesthesiology. 2009;110(1):166-81. doi: 10.1097/ALN.ob013e31819146a9. [PubMed: 19104184].

16. Varon J, Marik PE. Perioperative hypertension management. Vasc Health Risk Manag. 2008;4(3):615-27. doi: 10.2147/vhrm.s2471. [PubMed: 18827911]. [PubMed Central: PMC2515421].

17. Mammen MV, Tripathi M, Chandola HC, Tyagi A, Bais PS, Sanjeev OP. Comparison of enhancement of analgesic effect of intrathecal neostigmine by intrathecal clonidine and transdermal nitroglycerin patch on bupivacaine spinal anesthesia. Anesth Essays Res. 2017;11(4):993-7. doi: 10.4103/aer.AER_68_17. [PubMed: 29284862]. [PubMed Central: PMC5735501].

18. Sen S, Ugur B, Aydin ON, Ogurlu M, Gursoy F, Savk O. The analgesic effect of nitroglycerin added to lidocaine on intravenous regional anesthesia. Anesth Analg. 2006;102(3):916-20. doi: 10.1213/01.ane.0000195581.74190.48. [PubMed: 16492852].

19. Lauretti GR, Oliveira AP, Juliao MC, Reis MP, Pereira NL. Transdermal nitroglycerine enhances spinal neostigmine postoperative analgesia following gynecological surgery. Anesthesiology. 2000;93(4):9436. doi: 10.1097/00000542-200010000-00011. [PubMed: 11020743]. 